\title{
Evolución de los primeros escenarios sexuales de las jóvenes
}

\author{
José Luis Diéguez, Encarnación Sueiro y Antonio López-Castedo \\ Facultad de Ciencias de la Educación (Universidad de Vigo-Campus de Ourense)
}

\begin{abstract}
Resumen
Pretendemos conocer los cambios en los primeros escenarios sexuales, en 10 años. Estudio longitudinal, transversal y de tendencia sobre una muestra de 3223 (curso 97-98) y 1362 (07-08) universitarias, que realizaban primer y último curso en la Universidad de Vigo, utilizando una encuesta estructurada, anónima y voluntaria en la que se recogía la edad y variables referidas al primer coito, analizando con el SPSS 17.0. Las edades medias son 20.61 años $(97-98)$ y 20.96 años (07-08). El $40.9 \%$ y el $72,3 \%$ de las primeras y segundas, respectivamente habían iniciado sus coitos diferencias significativas $(\mathrm{p}<.05)-$, a los 18.42 y 17,41 años. También hay diferencias significativas $(p<.05)$ en el sexo de la primera pareja coital, relación existente con la misma, sentimiento experimentado, tiempo de conocimiento previo, mediación afectiva como motivo del primer encuentro, lugar donde aconteció, frecuencia y número de parejas durante el primer año, uso y tipo de protección y persona que propone.

Palabras claves: evolución, mujer, coitos.
\end{abstract}

\section{Objetivo}

Conocer las modificaciones ocurridas en los primeros escenarios sexuales, en las jóvenes, durante un período de 10 años.

\section{Material y Método}

Es un estudio longitudinal, diacrónico o transversal, por cuanto trata de analizar, para una población definida, cuáles son sus conductas sexuales en un determinado momento de tiempo, con sucesión de diversos momentos temporales, y de tendencia dado de que observan diferentes sujetos. Está desarrollado sobre una muestra de 3223 jóvenes universitarias, en el curso 1997-1998, y por 1362, del curso 2007-08) jóvenes universitarias que realizaban el primer y último curso, en el Campus de Vigo, de Ourense y de Pontevedra, de la Universidad de Vigo. A toda la población se le aplicó una encuesta estructurada, anónima y voluntaria para conocer variables de Identificación (Edad) y variables referidas al primer coito. Los datos son analizados con el programa estadístico SPSS 17.0.

\section{Resultados}

La edad media de las mujeres universitarias, del curso 97-98, es de 20.61 años (D.T.: 2.54) y la de las jóvenes universitarias, del curso 07-08, es de 20.96 años (D.T.: 2.91).

El 40.9\%, de las mujeres del curso 97-98, habían iniciado sus coitos, a una edad media de 18.42 años, lo mismo que acontecía para $72.3 \%$ de las chicas del curso 07-08, a una edad media de 17.41 años. Entre ambos grupos, se han encontrado diferencias significativas $\left(\chi^{2}=366.398 ; \mathrm{p}<0.001\right)$ en cuanto al porcentaje de comienzo, no así en cuanto a la edad de inicio $(\mathrm{t}=9.171 ; \mathrm{p}<0.01)$

El $86.5 \%$ de las mujeres, del curso 97-98, y el $91.2 \%$, del curso 07-08, iniciaron su primera experiencia coital con una persona de diferente sexo; sin embargo, un $12.9 \%$ de las primeras y un $8.0 \%$ de las segundas la comenzaron con una personas del mismo sexo. Hallamos diferencias significativas entre ambos grupos $\left(. \chi^{2}=14.961 ; \mathrm{p}<0.001\right)$.

En relación a la vinculación que tenían con la persona con quien realizaron ese primer coito, se pone de manifiesto que, el $88.0 \%$ de las mujeres, de la primera muestra y el $82.6 \%$, de la segunda, declararon que su primer coito fue con su novio; mientras el $8.9 \%$, de la primera muestra y el $12.3 \%$, de la segunda, lo realizó con un amigo, representando las restantes vinculaciones (esposo, prostituto $\mathrm{u}$ otras personas) una minoría del total en cada una de las muestras. Encontramos diferencias significativas $\left(\cdot \chi^{2}=30.684 ; \mathrm{p}\right.$ $=0.000)$ entre ambos grupos de mujeres.

Con respecto al tiempo de conocimiento previo de la persona con quien tuvieron el primer coito es, para el $43.1 \%$ de las mujeres del curso $97-98$ y para el $50.5 \%$ de las del curso 07-08 es mayor a 1 mes, pero menor de 1 año; sin embargo, los porcentajes referidos a 1 año o más de 1 año, representa un $49.7 \%$ en la primera muestra y un $39.7 \%$ en la segunda; y el tiempo de conocimiento inferior a un mes, revela un porcentaje de un $6.5 \%$ y un $9.1 \%$, respectivamente . Hallamos diferencias importantes entre ambos grupos $\left(\chi^{2}=\right.$ $28.81 ; \mathrm{p}=0.000)$.

El lugar más habitual para realizar la primera relación coital es la casa (propia o prestada), siendo los porcentajes, para las mujeres del curso 97-98, de $38.3 \%$ y $15.4 \%$, y para las del curso $07-08$, de $41.1 \%$ y $20.3 \%$, respectivamente. El coche lo emplean el $20.3 \%$ y el $18.7 \%$, respectivamente, el hotel $/ \mathrm{motel} /$ pensión, el $10.2 \%$ y el $6.0 \%$, respectivamente y los espacios públicos, el $8.5 \%$ y el $7.8 \%$, respectivamente. Hay diferencias significativas $\left(\chi^{2}=25.53 ; p=0.000\right)$ entre las mujeres de ambos grupos.

Por lo que respecta a los resultados referidos al consumo de alcohol en el primer coito, tenemos que el $81.4 \%$ de las chicas, del curso $97-98$, y el $79.2 \%$, de las del curso 07-08, no lo consumieron; mientras que un $17.6 \%$ de las primeras y un $20.1 \%$ de las segundas, sí confirmaron ingerir alcohol en esa primera relación. No se aprecian diferencias significativas entre ambos grupos $\left(\chi^{2}=2.35 ; \mathrm{p}=0.123\right)$.

El $66.0 \%$ de las mujeres de la primera muestra y el $55.1 \%$ de la segunda tuvo su primer coito porque 
estaba enamorada. Otros motivos relevantes alegados son: deseo $(52.7 \%$ y $48.7 \%$, respectivamente) y curiosidad $(21.0 \%$ y $19.8 \%$, respectivamente), puntuando las restantes razones elegidas (temor a perder a mi pareja, presionada por mi pareja, presionada por mi grupo de amistades y deseaba tener un hijo) con porcentajes más bajos. Los análisis estadísticos nos ponen de manifiesto que existen diferencias significativas entre las mujeres de ambos grupos en las motivaciones de estar enamorado-a $\left(\chi^{2}=\right.$ $28.509 ; \mathrm{p}=0.000)$ y presionado-a por mi pareja $\left(\chi^{2}=\right.$ $20.361 ; p=0.000)$; mientras que no se encuentran estas diferencias en sentír deseo $\left(\chi^{2}=3.204 ; p=0.073\right)$, tener curiosidad $\left(\chi^{2}=0.440 ; \mathrm{p}=0.507\right)$, temor a perder a mi pareja $\left(\chi^{2}=0.151 ; p=0.698\right)$, sentirse presionadao por mi grupo de amistades $\left(\chi^{2}=0.030 ; \mathrm{p}=0.861\right)$ y desear tener un hijo-a $\left(\chi^{2}=0.698 ; \mathrm{p}=0.403\right)$.

El $42.1 \%$ de las chicas del curso $97-98$ y el $51.4 \%$ de las del curso 07-08, se sintieron satisfechas en esa primera relación coital, existiendo un porcentaje elevado de mujeres de ambas muestras, que se percibió indiferente, insatisfecha, mal o preocupada. Hay diferencias significativas $\left(\chi^{2}=50.86 ; p=0.000\right)$ entre las mujeres de ambos grupos.

El $70.7 \%$ de las mujeres del curso $97-98$ y el $68.3 \%$, del curso 07-08, afirmaron no haber sentido orgasmo en su primera relación coital, mientras que un $27.9 \%$ y un $29.2 \%$, respectivamente, declararon haberlo tenido. No hemos encontrado diferencias significativas entre ambas muestras de mujeres $\left(\chi^{2}=0.730 ; \mathrm{p}=0.393\right)$.

El $39.4 \%$ de las del curso $97-98$ y el $34.4 \%$ de las del curso 07-08, tuvieron una frecuencia coital de 1 a 3 veces al mes durante el primer año; el 26,3\% y el $32,3 \%$ de la primera y de la segunda muestra, respectivamente, realizaron el coito de 1 a 3 veces a la semana $\mathrm{y}$, por último, 4 o más veces por semana, un $7.0 \%$ y un $10.9 \%$, respectivamente, apreciándose diferencias significativas $\left(\chi^{2}=33.71 ; \mathrm{p}=0.000\right)$ para ambos grupos, en esta variable.

El $82.3 \%$ de las chicas del curso $97-98$ y el $71.2 \%$ de las del curso 07-08, tuvieron una pareja sexual en el primer año de inicio coital; el $9.6 \%$ de la primera muestra y el $16.6 \%$ de la segunda, sostienen que realizaron el coito con dos parejas sexuales en ese primer año y un $6.0 \%$ y un $9.1 \%$, respectivamente, tuvieron tres o más parejas. Encontramos diferencias significativas $\left(\chi^{2}=43.42 ; \mathrm{p}=0.000\right)$ entre ambos grupos .

Con respecto al mecanismo de protección, el $86.3 \%$ de las del curso $97-98$ y el $91.3 \%$, de las del curso $07-$ 08 , afirmaron haber usado método de protección en su primer coito; sin embargo, un $12.8 \%$ de las mujeres de la primera muestra y un $6.0 \%$ de la segunda muestra, aseguraron que no lo emplearon, hallando diferencias significativas $\left(\chi^{2}=28.58 ; \mathrm{p}=0.000\right)$ entre las mujeres de ambos grupos.

El $87.2 \%$ de las mujeres del curso $97-98$ y el $95.2 \%$ de las mujeres del curso 07-08 emplearon el preservativo y el $4.5 \%$ de las mujeres de la primera muestra y el $0.8 \%$ de las de la segunda utilizaron el coito interrumpido. Los restantes primeros métodos de protección (natural, espermicida, D.I.U., esponja, diafragma y hormonal) apenas fueron utilizados, por cualquiera de las dos muestras. El análisis estadístico $\left(\chi^{2}=43.474 ; p=0.000\right)$ nos muestra que existen diferencias significativas entre ambos colectivos de mujeres.

El 93.3\% de las mujeres del curso 97-98 y el 91.5\%, del curso 07-08 indicaron no haber tenido problemas con el uso del primer método de protección, sin embargo, un $6.2 \%$ de las primeras, y un $7.3 \%$ de las segundas, sí los tuvieron, no encontrando diferencias significativas $\left(\chi^{2}=4.98 ; \mathrm{p}=0.083\right)$ en función del año académico analizado.

Observamos que el $46.3 \%$ de las mujeres del curso 97-98, y el 49.6\%, de las del curso 07-08 manifestaron que la propuesta del método anticonceptivo la hicieron ellas mismas, a su vez, un $31.2 \%$ de las primeras y un $35.7 \%$ de las segundas aseguraron que fue su pareja; mientras que un $21.1 \%$ y un $12.4 \%$, respectivamente, indicaron que fue propuesto por ambos miembros de la pareja, observándose diferencias significativas entre ambos grupos de mujeres $\left(\chi^{2}=27.77 ; \mathrm{p}=0.000\right)$.

\section{Conclusiones}

En la investigación que se lleva a cabo, con mujeres universitarias que tienen una edad media de 20-21 años, se observa que en torno al $40 \%$, de las mujeres del curso 97-98, habían iniciado sus coitos, a una edad media de 18.42 años, y al $72 \%$ de las del curso $07-8$, a una edad media de 17.41 años, produciéndose un incremento significativo en el número de jóvenes que iniciaron los coitos,. Así como una bajada en la edad de comienzo, aunque ésta no es relevante..

El $86.5 \%$ de las del curso 1997-98 tuvieron su primer coito con una persona de diferente sexo, incrementándose a un $91.2 \%$ en las mujeres del curso 2007-08. Consecuentemente, el porcentaje de parejas sexuales del mismo sexo decrece de la primera muestra $-12.9 \%$ - a la segunda $-8.0 \%$. En esta misma dirección, Doval et al. (1987). afirman que un $8.1 \%$ de las mujeres habían tenido experiencia homosexual en alguna ocasión y un $20.3 \%$ de las mismas no responden a esta pregunta. En el IJE-2008 la tasa global de homosexualidad y de bisexualidad reconocida entre los y las jóvenes en España se sitúa en el 3.5\%, entre las mujeres dicha tasa seria del $3.0 \%$. Si se analizan los diferentes IJEs, desde el año 2000, las tasas de homosexualidad se van incrementando, pasando de un $1.5 \%$ para las mujeres en el año 2000 a un $2.2 \%$ para las mujeres en el año 2008. Sin embargo, otras investigaciones la sitúan en un 6.3\% (Comas, 2008), que se asemeja al encontrado con la muestra del curso 2007-08. Por su parte, la tasa de relaciones homosexuales en la encuesta sobre hábitos sexuales del INE es de un $3.3 \%$, al menos una vez en la vida, en el conjunto de la población entre 18/49 años, y para las mujeres sería de un $2.7 \%$. 
Si nos centramos en la variable relación existente con la primera pareja sexual, en ambas muestras fue con el novio, aunque los porcentajes decrecen significativamente de las mujeres del curso 1997-98 $88.0 \%$ - a las del curso 2007-08 -82.6\%-; consecuentemente, se incrementó de manera significativa, el porcentaje de mujeres que lo realizaron con una amistad. Los estudios con muestras universitarias de nuestro país, García et al (1995), afirman que las universitarias navarras inician su primer relación coital fundamentalmente con su novio, seguidos por el grupo de mujeres que lo hacen con un amigo y ninguna de ellas la realizan con un prostituto. Sueiro y Diéguez (2001), señalaban que el $89.6 \%$ de las mujeres mantuvieron su primer coito con su novio y sólo el 7.7\% con un amigo. Ambos estudios concuerdan con los resultados encontrados con las mujeres del curso 1997-98.

Con poblaciones de adolescentes españolas, la investigación llevada a cabo por López et al. (1993), indica que el $95.8 \%$ de las mujeres inician su vida sexual en el marco de una relación estable y, Robledo et al. (2007), destacan que el $87.6 \%$ de las mujeres mantuvieron su primer coito con su pareja, porcentaje algo superior al encontrado por nosotros en las mujeres del curso 2007-08.

En relación al tiempo que hacía que conocía a la persona con quién aconteció esa primera relación coital, para la muestra del curso 1997-98, el porcentaje más alto $-49.7 \%$ - se encuentra en el intervalo de 1 año o más tiempo, que desciende $-39.7 \%$ - en la muestra del curso 2007-08, sin embargo, para esta última muestra, el porcentaje más elevado $-50.5 \%$ corresponde a quienes afirmaron conocer a su pareja sexual en el intervalo de tiempo que va desde más de un mes a menos de un año, porcentaje superior al de la muestra del curso $1997-98$, que era de un 43.1\%. Los cambios acontecidos en esta variable, después de diez años, son significativos. Resultados similares al encontrado con las mujeres del curso 1997-98, se reflejan en la investigación de Sueiro y Diéguez (2001), dado que el 49.5\% de las mujeres conocían a su primera pareja coital desde hacia más de un año, y el $44.5 \%$ de las mujeres entre 1 mes y 1 año.

Por lo que se refiere a la variable lugar donde ocurrió el primer coito, se pone de manifiesto que la casa propia o prestada es la más elegida - del $53.7 \%$ de los sujetos de la primera muestra se pasa al $61.4 \%$ de la segunda-, seguido del coche $-20.3 \%$ y $18.7 \%$, respectivamente-. Los cambios acontecidos tras diez años de evolución son significativos, aumentando o disminuyendo, según los casos. No se encuentran estudios para comparar que tengan en cuenta el lugar donde la mujer realizó el primer coito.

Cuando analizamos el consumo de alcohol en la mujer o por parte de su pareja en el primer coito, en torno al $80 \%$ de cada una de las muestras indican que no lo consumieron, sin embargo, un $17.6 \%$ de las mujeres del curso $1997-98$ y un $20.1 \%$ de las mujeres del curso 2007-08 refieren consumirlo. No encontramos otros estudios que nos permitan realizar un análisis comparativo en esta variable.

En cuanto a la variable referida a las razones por las que realizaron ese primer coito, se percibe que la que aglutina un mayor porcentaje de sujetos es el estar enamorada, para ambas muestras $-66.0 \%$ de la primera muestra y el $55.1 \%$ de la segunda-, seguida del deseo el $52.7 \%$ y el $48.7 \%$, respectivamente-, encontrando diferencias significativas sólo en el primer caso. Los resultados encontrados están en la misma dirección que los obtenidos por otras investigaciones, ya que el principal motivo en las mujeres para realizar el primer coito es, fundamentalmente, el amor. Así, Repossi et al. (1993), indican que el motivo más frecuente para mantener esta primera relación coital en el caso de las chicas es por cuestión de amor.

Respecto a la variable de cómo se sintieron en la primera relación coital, se pone de manifiesto que un $42.1 \%$ de las mujeres del curso 1997-98 se sintieron satisfechas incrementándose este porcentaje significativamente a un $51.4 \%$ para las mujeres del curso 2007-08. En esta línea, Arnaldos y Hernández (1996), sobre una muestra de 285 mujeres gestantes, mencionan que el $77 \%$ de las gestantes relatan una vivencia placentera, con o sin orgasmo, de este primer contacto coital, porcentaje bastante superior al encontrado con las mujeres del curso 1997-98. Lasheras et al. (2005), anotan que el $39.4 \%$ de las mujeres sintieron placer en su primer coito, el resto de las encuestadas percibieron indiferencia $(0.13 \%)$, insatisfacción $(7.1 \%)$ o dolor $(43.17 \%)$, porcentajes inferiores al encontrado con las mujeres del curso 2007-08. Finalmente, Rodríguez y Traverso (2007), manifiestan que el sentimiento en la primera relación coital en un $34.2 \%$ de las mujeres lo valoran como satisfactoria o muy satisfactoria (inferior al de la muestra del curso 2007-08), un 27.4\% de las mujeres se percatan de que se trata de una relación insatisfactoria o muy insatisfactoria (reafirma el porcentaje de la muestra del curso 2007-08), y un $38.4 \%$ de mujeres la relación no dejó especial huella en esta línea (ni satisfactoria ni insatisfactoria).

Respecto a la variable consecución del orgasmo en el primer coito, el 70.7\% de las mujeres del curso 199798 y el $68.3 \%$, del curso 2007-08, refirió no haberlo sentido. Arnaldos y Hernández (1996), manifiestan que el $12 \%$ llegaron al orgasmo, mientras que la opción más contestada fue el placer sin orgasmo $65 \%$, y dolor físico en la cuarta parte de las mujeres, siendo estos porcentajes inferiores a los hallados en esta investigación en el grupo de mujeres del curso 199798. Sin embargo, Sueiro y Diéguez (2001), indicaban que sólo el $29.7 \%$ de las mujeres sintieron orgasmo en el primer coito, porcentajes similares a los del curso 1997-98.

Si analizamos la variable relativa a la frecuencia con que aconteció el coito durante el primer año, se observa que los mayores porcentajes, para ambos cursos, se 
encuentran en el intervalo de 1 a 3 veces al mes $-39.4 \%$ de las mujeres del curso 1997-98 y disminuye a un $34.4 \%$ de las mujeres del curso 2007-08-, siendo significativa la diferencia con el paso del tiempo. Sueiro y Diéguez (2001), señalan que para un $41.8 \%$ de las mujeres la frecuencia con que mantuvieron coito en el año que lo iniciaron fue de 1 a 3 veces al mes, para un $23.1 \%$ de 1 a 3 veces a la semana y para un $16.5 \%$ menos de 1 vez al mes, resultados que reafirman los encontrados con del curso 1997-98.

Si nos centramos en la variable número de parejas coitales que tuvieron durante el año en que iniciaron sus coitos, el porcentaje más elevado se observa en tener una única pareja -el $82.3 \%$ de las mujeres del curso $1997-98$ y desciende a un $71.2 \%$ para las del curso 2007-08. Por el contrario, el número de estudiantes que tuvieron más de una pareja coital se incremento de un $15.6 \%$, en la primera muestra, al $25.7 \%$, en la segunda. Los cambios acontecidos en esta variable, tras diez años de evolución, son significativos. La investigación de López (1990) también reseña que las mujeres tienen el mayor porcentaje en una única pareja, apoyando los resultados del curso 1997-98; sin embargo los resultados de Robledo et al. (2007) en los que se aprecia que el $79.4 \%$ de las mujeres mantuvieron coitos exclusivamente con su pareja.

Si nos fijamos en el uso de métodos de protección por parte de las mujeres en su primera relación coital, se observa un incremento significativo en su uso después de 10 años, pasándose de un $86.3 \%$ a un 91.3\%. Lasheras et al. (2005), precisan que entorno al $90 \%$ de las mujeres utilizaron algún método anticonceptivo en el primer coito, resultados que están en la misma línea del curso 2007-08. Sin embargo,

El método más utilizado en la primera relación coital por parte de las mujeres del curso 1997-98 y del curso 2007-08 es el preservativo (87.2\% y 95.2\%, respectivamente), seguido a bastante distancia por el coito interrumpido ( $4.5 \%$ y $0.8 \%$, respectivamente), los hormonales (4.0\% y $1.4 \%$, respectivamente) y los restantes apenas tienen presencia. El uso mayoritario del preservativo en la primera relación coital por parte de las mujeres es un dato que se reitera en todas las investigaciones, sin embargo, los porcentajes de uso, cambia según el tipo de población, origen, momento de la historia, entre otros. Así, Oraá (1996), afirma que en un $66 \%$ de las mujeres utilizaron el preservativo y en un $20 \%$ de los casos utilizaron uno ineficaz, porcentaje inferior al encontrado con la muestra del curso 199798; Sueiro y Diéguez (2001), recalcan que el $87.7 \%$ de las mujeres utilizaron en su primer coito el preservativo y un $4.9 \%$ el coito interrumpido, datos que ratifican los del curso 1997-98; en el estudio del INE-2002, se afirma que un $81.2 \%$ de las mujeres utilizaron preservativo en su primer coito, porcentaje algo inferior al de las mujeres del curso 1997-98, esto puede ser debido a que en esta muestra la media de edad es más elevada que la de nuestra investigación.
Si hacemos referencia a como se utilizó la anticoncepción en el primer coito, se observa que un 93.3\% de las mujeres del curso $1997-98$ y un $91.5 \%$ de las mujeres del curso 2007-08 no tuvieron problemas con el uso de la misma, no encontrando ningún cambio significativo después de 10 años. En la investigación de Sueiro y Diéguez (2001), se constata que el 91.2\% de las mujeres no tuvieron problemas con el método anticonceptivo en el primer coito, porcentaje similar al encontrado con el alumnado del curso 1997-98.

Respecto a quien propuso el uso de anticoncepción en el primer coito, para un $46.3 \%$ de las mujeres del curso $1997-98$ y para un $49.6 \%$ de las mujeres del curso 2007-08 fueron ellas mismas y sólo un $21.1 \%$ de las primeras y un $12.4 \%$ de las segundas fue un decisión consensuada por los dos. En el trabajo de Sueiro y Diéguez (2001), se resalta que el $49.0 \%$ de las mujeres propusieron ellas mismas el uso de la anticoncepción en la primera relación coital, porcentaje similar al hallado con las mujeres universitarias del curso 1997-98.

En síntesis, Considerando los cambios evolutivos experimentados por las jóvenes en los últimos años, relacionados con su Salud Sexual y Reproductiva, se hace necesario desarrollar programas educativos que promocionen aquella y que reduzcan los riesgos asociados a su práctica, desde los diferentes agentes educativos y ámbitos psico-socio-sanitarios. Y, todo ello, desde la infancia.

\section{Referencias}

Arnaldos, J. y Hernández, J. (1996). La sexualidad femenina vista desde el embarazo (I). Cuadernos de Medicina Psicosomática y Psiquiatría de Enlace, (40), 14-21.

Ayuntamiento de Málaga. Delegación de juventud.

Casco, F. J. y Oliva, A. (2005). Valores y expectativas sobre la adolescencia: discrepancias entre padres, profesores, mayores y adolescentes. Infancia $y$ Aprendizaje, 28 (2), 209-220.

Cassamo, H., Planes, M., y Gras, M.E. (2008). Uso del preservativo en estudiantes de secundaria de Mozambique. Cuadernos de Medicina Psicosomática, (86-87), 60-68.

Comas, D. (2008). Informe de la juventud en España. Madrid: Ministerio de Trabajo y Asuntos Sociales.

Croockett, L.J., Raffaelli, M., y Moilanen, K. (2003). Adolescent sexuality: Behavior and meaning. En G.R. Adams y M. D. Berzonsky (Eds.), Blackwell handbook of adolescence (pp.330-348). Oxford: Blackwell Publishing.

Doval, J.L., Perdiz, C., Seare, M. M., Sueiro, E., y Valencia, L. (1987). La sexualidad en adolescentes en Ourense. Actas III Congreso Estatal de Planificación Familiar. Valladolid, 59.

García, J.L., Avis, M., Cobos, F., Biurrum, A.C., Eslava, J.L., Rodrigo, C., Padilla, B., y Tinajas, M.R. (1995). Conductas sexuales de riesgos en universitarios-as: Un estudio en la Universidad 
Pública de Navarra. Cuadernos de Medicina Psicosomática y Psiquiatría de Enlace, (36), 48-60.

INE (2002). Avance del censo de población de 2001. Madrid: Instituto Nacional de Estadística.

Injuve, (2000). Informe de la Juventud en España 2000. Madrid: Ministerio de Trabajo y Asuntos Sociales.

Injuve, (2001). Sondeo periódico de opinión y situación de la gente joven. Segundo trimestre 2001. Madrid: Ministerio de Trabajo y Asuntos Sociales.

Injuve. (2004). Condiciones de vida y situación de los jóvenes en España. Informe de juventud en España 2004. Madrid: Ministerio de Trabajo y Asuntos Sociales.

Injuve, (2004). Informe Juventud en España (2004). Madrid: Ministerio de Trabajo y Asuntos Sociales.

Injuve, (2004). Sondeo de opinión y situación de la gente joven. Segunda encuesta de 2004. Madrid: Ministerio de Trabajo y Asuntos Sociales.

Injuve, (2008). Informe Juventud en España (2008). Madrid: Ministerio de Trabajo y Asuntos Sociales.

Injuve-Cis, (2002). Informe Juventud en España (2002). Madrid: Ministerio de Trabajo y Asuntos Sociales.

Ford, K., Shon, W., y Lepkowski, J. (2001). Characteristics of adolescent's sexual partners and their association with use of condoms and other contraceptive methods. Family Planning Perspectives, 33, 100-105.

Forrest, J.D. y Singh, S. (1990). The sexual and reproductive behavior of American women, 19821988. Family Planing Perspectives, (22), 206-214.

Lasheras, M.G., Cuñe, J., Bautista J., y Farré J.M. (2005). Hábitos sexuales en jóvenes universitarios. Cuadernos de Medicina Psicosomática y Psiquiatría de Enlace, (74), 57-63.

López, F., Lévy, J.J., Samson, J.M., Frigault, S.A., Lamer, S.A., y Lew, V. (1993). Actitudes y comportamientos sexuales frente al SIDA en un grupo de estudiantes españoles: Estudio preliminar. Cuadernos de medicina psicosomática y psiquiatría de enlace, (25), 41-51.

Malo de Molina, C. (1992). Los españoles y la sexualidad. Madrid: Temas de Hoy.

Miller, B.C., Benson, B., y Galbraith, K. A. (2001). Family relationships and adolescent pregnancy risk: A research synthesis. Developmental Review, (21), 1-38.

Navarro, E., Reig, A., y Barberá E. (2006). Grupo de iguales e iniciación sexual adolescentes: diferencias de género. International Journal of Clinical and Health Psychology, 6 (1), 79-96.

Oman, R.F., Vesely, S.K., Aspy, C.B., McLeroy, K.R., y Luby, C.D. (2004). The association between multiple youth assets and sexual behavior. Americam Journal of Health Promotion, 19 (1), 12-18.

Repossi, A., Araneda, J.M., Bustos, L., Puente, C., y Rojas, C. (1993). El estudiante universitario frente al sexo: ¿Qué piensa, qué sabe, qué haces? Revista Médica de Chile, (21), 201-208.
Robledo, A., López, S., Sánchez I., Del Río, L., y Barrera, E. (2007). Conocimientos y comportamientos sexuales de los adolescentes escolarizados en Parla. Sexología Integral, 4 (2), 7379.

Rodríguez, J. y Traverso, C.I. (2007). Conductas y Educación sexual en universitarios españoles. Málaga: Grupo Editorial.

Rostosky, S.S., Korfhage B.A., Duhigg, J.M., Stem A.J., Bennett, L., y Riggle, E.D. (2004). Same-sex couple perceptions of family support: a consensual qualitative study. Family Process, 43 (1), 43-57.

Savin-Williams, R.C. y Diamond, L. (2004). Sex. En R. Lerner y L. Steinberg (Eds.), Handbook of adolescent psychology ( $2^{\mathrm{a}}$ ed., pp. 189-231). New York: Wiley.

Sueiro, E. y Diéguez J.L. (2001). Juventud y sexualidad (pp. 257-269). Actas do VI Congreso Galaico-Português de Psicopedagogía. Braga

Zani, B. y Cicognani, E. (2006). Sexuality and intimate relationships in adolescence. En S. Jackson y L. Goossens (Eds.), Handbook of Adolescent Development (pp. 200-222). East Sussex: Psychology Press. 